\title{
Produção de infográficos na Educação de Jovens e Adultos: um estudo do letramento multissemiótico a partir de mídias 2.0
}

\author{
Valéria Machado da Costa - UFRGS - costavm@gmail.com \\ Clevi Elena Rapkiewicz - UFRGS - clevirap@gmail.com \\ Liliana Maria Passerino - UFRGS - liliana@cinted.ufrgs.br \\ Liane Margarida Rockenbach Tarouco - UFRGS - liane@penta.ufrgs.br
}

\begin{abstract}
Resumo. A disponibilidade de informação em diferentes mídias e formatos provoca a necessidade de ajustes nos processos de letramento. À escola, como principal agência de letramento dos alunos, cabe ofertar a estes experiências que os levem a desenvolver habilidades e competências para leitura e escrita de textos multimodais. Neste sentido, foi desenvolvido um projeto junto a uma turma de Educação de Jovens e Adultos, de um Colégio de Aplicação, no segundo semestre de 2012. O projeto visava ao letramento multimodal destes alunos por meio da produção de infográficos utilizando, como recurso, o Prezi. A análise do material produzido mostrou que mídias 2.0 como Prezi são adequadas para este tipo de trabalho pois foram encontradas evidências de letramento multimodal nos alunos participantes do estudos. A pesquisa também mostrou que o domínio de um gênero multimodal, assim como um gênero textual, demanda tempo e atividades contínuas por parte dos professores.
\end{abstract}

Palavras-chave: letramento multissemiótico; infográfico; web 2.0

Abstract. The availability of information in different media and formats causes the need for adjustments in the processes of literacy. At school, as lead agency for literacy students, it is offering these experiences that lead them to develop skills and competencies for reading and writing multimodal texts. Therefore, a project was developed together with a group of Youth and Adults, a School of Application, in the second half of 2012. The project aimed to multimodal literacy of these students through the production of infographics using as a resource, Prezi. The analysis showed that the material produced 2.0 as Prezi media are suitable for this kind of work because it found evidence of multimodal literacy in students participating in the study. The survey also showed that the domain of a multimodal genre, as well as a genre, takes time and ongoing activities by teachers.

Keywords: multimodal literacy; infographics; web 2.0

\section{Introdução}

A cada dia aumenta o volume de informações disponíveis por meio de diferentes dispositivos (celulares, tablets, notebooks etc.). Distintos em suas funcionalidades principais, e, sobretudo, na sua facilidade de uso em situações do quotidiano, cada um destes dispositivos possui algo em comum: a interface com o leitor por meio da tela, que se utiliza de metáforas poderosas (desde o desktop até telas sensíveis ao toque que permitem que qualquer um navegue por meio de toques na tela) que buscam facilitar a interação entre usuário e sistema.

E esta tela, diferentemente do livro impresso, enseja novas configurações e integrações entre os diferentes modos (formas de representação do conhecimento como texto escrito, imagem estática, som, vídeo, cor). Isto porque o livro impresso, até hoje o principal responsável pela difusão do conhecimento, pertence, em grande parte, ao domínio da linguagem verbal escrita, onde à imagem é dado o papel secundário, de ilustração (ressalvas feitas aos livros de artes, arquitetura e outras áreas que são notadamente visuais). 
Como aponta Kress (2011), à imagem é dada uma função secundária não só pela crença de que usando a linguagem escrita é possível explicar tudo, mas também pelo fato de que imprimir imagens (principalmente se demandam cor) é mais caro e, durante muito tempo, exigia uma tecnologia mais avançada.

A digitalização da informação mudou este cenário ao tornar iguais modos como texto, imagem estática, imagem animada e som, possibilitando seu uso em diferentes momentos e para fins distintos. Uma breve navegação por sites noticiosos ou educacionais, ou a leitura de revistas e jornais impressos mostra que o texto verbal, organizado em linhas e parágrafos, vem cada vez mais dividindo seu espaço com outros modos e outra forma de apresentar o conteúdo.

Não é mais a interface livro o "modelo" a ser seguido, mas a interface tela; cada vez mais materiais impressos adotam o "estilo online" com diferentes formas de "leitura/navegação" pelas páginas; cada vez mais outros modos são acrescentados ao impresso (seja no próprio papel, com o uso cada vez maior de imagens, seja na inclusão de cds, dvds ou endereços online onde o leitor pode ter mais conteúdo mutimodal sobre aquele assunto).

E essa mudança, mesmo que não tão rápida quanto em outros setores, também pode ser vista na educação. Um exemplo é o edital Plano Nacional do Livro Didático de 2014 (PNLD/2014) que irá aceitar dois tipos de coleções: a do tipo 1, composta por um conjunto de livros impressos; e a do tipo 2, composta por um conjunto de livros impressos acompanhados de conteúdos multimídia, dentre os quais é citado o infográfico (BRASIL, 2011).

Mas se no dia a dia o aluno está cada vez mais em contato com estes dispositivos e esta nova forma de comunicação, é preciso que também a escola integre ao seu currículo esses elementos. Neste sentido, se consideramos a escola a principal agência de letramento do aluno, e que letramento diz respeito aos usos sociais da leitura e escrita (KLEIMAN, 2008, ROJO, 2009), é fundamental que a escola ofereça oportunidades do aluno desenvolver habilidades e competências neste campo, denominado por Rojo (2009) como letramento multissemiótico ou, numa tradução direta de autores como JEWITT e KRESS (2008), letramento multimodal (multimodal literacy).

Visando ao desenvolvimento destas habilidades, o presente artigo apresenta o resultado de uma pesquisa feita com alunos da EJA (educação de jovens e adultos) de um Colégio de Aplicação, numa parceria entre professor de informática e de teatro, no sentido de produzir um texto multimodal (mais precisamente um infográfico), como resultado de um projeto intitulado Poéticas do Corpo. Neste trabalho, os alunos deveriam enfatizar características corporais das pessoas em diferentes modalidades artísticas: como numa dança, no teatro ou na TV.Nesse contexto, este artigo está organizado da seguinte forma: na seção 1 é abordado o conceito de letramento multissemiótico; na seção 2 elencam-se as características do Prezi e o porquê de sua escolha para a pesquisa. Na seção 3 é apresentado o estudo feito e discutem-se os resultados obtidos em dois trabalhos.

\section{Letramento multissemiótico}

O termo letramento, tradução da palavra inglesa literacy (the quality or state of being literate $^{1}$ ), é usado para caracterizar a dimensão social, pragmática, dos processos de leitura. Para Mayer (2008, p. 339, tradução nossa), "letramento envolve a habilidade de 
gerar comunicações que outros possam compreender e compreender comunicações geradas por outras pessoas”.

Para Jewitt e Kress (2008), o letramento multimodal, ou multissemiótico, é o letramento que leva em consideração a gama de modos de representação da informação que as pessoas usam para aprender, se comunicar e moldar o conhecimento em seus contextos sociais. Modo aqui entendido como um recurso semiótico com diferentes potenciais e limitações materiais e culturais para criar significado, moldado pelo contexto social e cultural (affordances). Imagem, escrita, música, layout e objetos 3D são exemplos de modos utilizados na representação da informação e na comunicação (KRESS, 2010).

Nesse sentido, qualquer evento comunicativo ${ }^{2}$ envolve diferentes modos. E o significado de uma mensagem é composto por diferentes aspectos de cada um dos modos que a compõem. Assim, "cada modo é parcial em relação à totalidade do sentido - incluindo a fala e a escrita” (JEWITT, KRESS, 2003, p. 3).

Se analisarmos o contexto em que vivemos, permeado pelo digital e pelas telas, percebe-se que, cada vez mais, a imagem torna-se um elemento importante e, por que não dizer central, nas mensagens veiculadas (tanto no suporte digital quanto no impresso). Desta forma, desenvolver no aluno habilidades e competências para a leitura e escrita de textos multissemióticos é prepará-lo para ser um cidadão crítico e ativo.

Consequentemente, se a escola quer formar cidadãos críticos e capazes de atuar de forma ativa na sociedade, é preciso, como aponta Rojo (2009, p. 108), “ampliar e democratizar tanto as práticas e eventos de letramento que têm lugar na escola como o universo e a natureza dos textos que nela circulam”, de modo a abarcar outros códigos para além do texto escrito.

Isto porque a aquisição do letramento não se restringe a uma questão de educação, mas é, também, de poder. $\mathrm{O}$ acesso às habilidades e conhecimentos necessários para a criação de conteúdos multimodais é um fator decisivo entre ser um autor na rede, atuante e reflexivo, ou ser apenas um receptor do conteúdo produzido (WARSCHAUER, 2006).

Segundo Rojo (2009, p. 107), se pensarmos nos textos contemporâneos veremos que é necessário ampliar a noção de letramento de modo a incluir "o campo da imagem, da música, das outras semioses” e não somente a escrita.

Mas, para que estas habilidades e competências sejam desenvolvidas, não adianta somente ler textos multimodais, é preciso também produzi-los. No caso desta pesquisa, optou-se pela produção de infográficos, por ser um formato que, por definição, propõe a integração entre os modos texto e imagem. Além disso, como aponta Teixeira (2010), um infográfico pressupõe uma narrativa, conta uma história (o que o diferencia de um gráfico, mapa ou uma tabela isolados). Desta forma, ele pode ser utilizado didaticamente para explicar um conteúdo. Como afirma a autora, o infográfico caracteriza-se por uma:

[...] inter-relação indissolúvel entre texto (que vai além de uma simples legenda ou título) e imagem que deve ser mais que uma ilustração de valor essencialmente estético, por exemplo, mas algo que tenha o propósito claro de contribuir para a construção e consequente compreensão plena desta narrativa (TEIXEIRA, 2010, p. 33).

Assim, para a criação dos infográficos, optou-se pelo Prezi.

\section{Uso do software Prezi para criação de infográficos}


4

Há muitos softwares que podem ser utilizados para criação de infográficos. Os mais conhecidos entre os profissionais são o Flash e o Adobe Illustrator. No entanto, além de serem proprietários, o que impede seu uso em muitas escolas públicas, estes aplicativos, por serem profissionais, são complexos e demandam não só mais tempo de capacitação mas também um uso periódico do mesmo pelos usuários para que haja uma proficiência em seu manuseio.

Dentre os softwares gratuitos existentes que poderiam ser utilizados para criação do infográfico (Glogster Edu, Gimp, dentre outros), foi selecionado o Prezi com base nos seguintes critérios.O primeiro deles diz respeito a sua interface simples e de fácil compreensão, como pode ser visto na Figura 1.

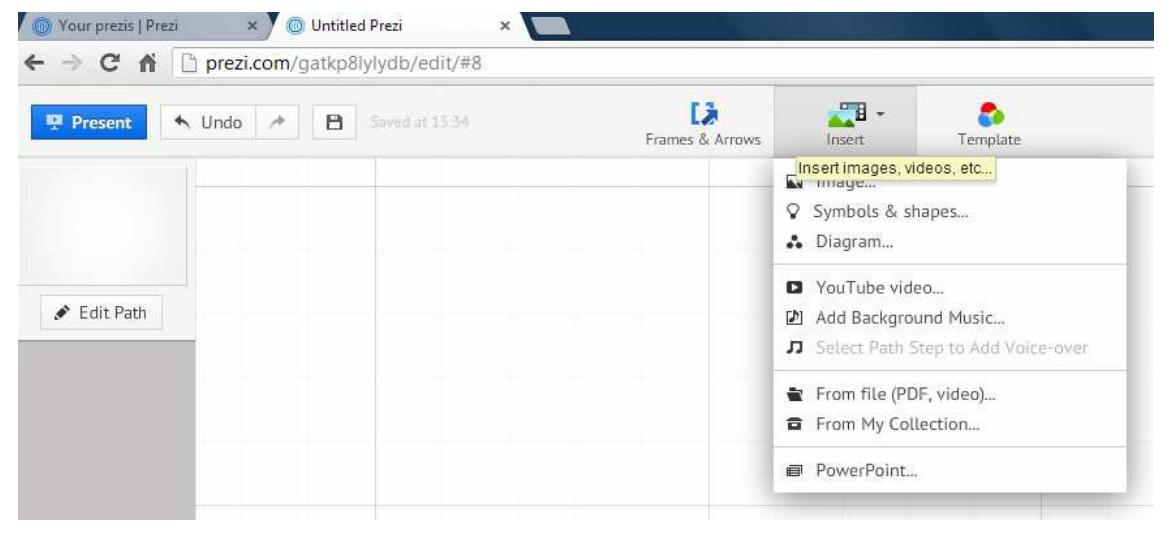

Figura 1 - Tela inicial do Prezi

A redução e clareza nas opções (como mostra a Figura 2, há somente três opções no menu principal) é especialmente útil quando se trata de estudantes que não possuem uma fluência digital (caso das turmas da EJA do colégio onde foi feita a pesquisa) e quando não há um tempo longo para aprendizagem do software, o que é comum na educação, quando o software é um meio utilizado para um fim pedagógico e não um fim em si mesmo. Esta concisão também está presente no Glogster Edu, mas neste caso, a ferramenta oferece menos opções interessantes do que o Prezi. Já o Gimp apresenta muitas opções (por ser um programa de edição de imagem), o que pode confundir o usuário menos experiente.

O segundo ponto é o fato do Prezi oferecer alguns templates, o que facilita a construção de infográficos e outros produtos visuais, principalmente por um público mais leigo em relação à gramática visual, isto é, à forma de distribuição dos modos em uma tela. O que não ocorre no Glogster Edu e no Gimp.

O terceiro é que, além da oferta de templates, o Prezi também possibilita a inclusão de diferentes modos, como texto escrito, imagem estática, vídeo, diagramas, símbolos, formas e som, além do usuário poder desenhar linhas e setas, por exemplo. Com esta variedade de modos, o Prezi torna-se uma ferramenta que oferece muitas possibilidades de composição e produção de textos multimodais.

O quarto ponto refere-se à possibilidade de criar uma navegação entre os elementos disponíveis na tela. Assim, o leitor pode navegar pelo conteúdo criado no Prezi de forma aleatória (clicando sobre o elemento a ser lido) ou seguir o caminho sugerido pelo autor. A criação de caminhos pode contribuir para a compreensão do conteúdo apresentado, sendo, a nosso ver, uma opção interessante para o ambiente escolar. O Gimp também permite a criação de "botões" de navegação por meio de mapa de imagens (COSTA, TAROUCO e BIAZUS, 2011). 
5

O quinto ponto é a possibilidade de colaboração, característica fundamental das mídias $2.0^{3}$, que permite que o conteúdo seja compartilhado com outras pessoas e que estas possam também editá-lo, o que facilita o trabalho colaborativo não só em sala de aula, mas também a distância. O próprio professor pode estar habilitado para edição do conteúdo, podendo acrescentar comentários diretamente ao trabalho realizado. Nem o Glogster Edu nem o Gimp oferecem esta opção de compartilhamento do conteúdo para edição.

Há também o que denominamos aqui de "elementos operacionais", isto é, funcionalidades desta ferramenta que são úteis a professores e alunos: i) importar apresentações do Power Point (facilitando a reutilização de conteúdos desenvolvidos com este software, que é muito utilizado por alunos e professores); ii) imprimir em pdf (o que permite imprimir o conteúdo produzido para ser analisado em sala de aula, sem necessidade de usar o computador); iii) fazer login com o Facebook e compartilhar nesta rede social. O Glogster Edu também permite vários tipos de compartilhamento e impressão; o Gimp não oferece compartilhamento por ser um programa de desktop, mas também permite que o conteúdo possa ser impresso. Vale lembrar que o compartilhamento de conteúdo é também uma característica importante da Web 2.0.

No caso do Facebook, o Brasil é o segundo país com mais usuários, perdendo apenas para os $\mathrm{EUA}^{4}$, sendo assim, é provável que alguns alunos e professores já tenham conta nesta rede e possam reutilizar seus logins e senhas. Além disso, é possível compartilhar o conteúdo desenvolvido no Prezi no Facebook, permitindo que o professor amplie seu trabalho utilizando redes sociais em sua prática pedagógica, como a criação de um grupo. O aluno também pode divulgar em seu perfil os trabalhos desenvolvidos em sala de aula, o que pode constituir-se em uma motivação a mais.

Neste item, vale lembrar que o Prezi facilita que os conteúdos sejam disponibilizados sob a licença Creative Commons, o que facilita a reutilização do mesmo por outras pessoas bem como a criação de obras derivadas ${ }^{5}$.

Por fim, uma outra funcionalidade do Prezi é a possibilidade de fazer download do material produzido em Flash, o que permite que este seja também apresentado em ambientes onde não haja rede disponível. O Quadro 1 apresenta um resumo destas características.

\section{Quadro 1 - Comparação entre o Prezi, Glogster Edu e Gimp}

\begin{tabular}{|l|l|c|c|c|c|c|c|}
\hline & $\begin{array}{c}\text { Platafor- } \\
\text { ma }\end{array}$ & $\begin{array}{c}\text { Interface } \\
\text { simples }\end{array}$ & $\begin{array}{c}\text { Uso de } \\
\text { templates }\end{array}$ & $\begin{array}{c}\text { Suporte } \\
\text { para } \\
\text { diferentes } \\
\text { modos }\end{array}$ & $\begin{array}{c}\text { Navega- } \\
\text { ção }\end{array}$ & $\begin{array}{c}\text { Colabora- } \\
\text { ção }\end{array}$ & $\begin{array}{c}\text { Elementos } \\
\text { operacionais }\end{array}$ \\
\hline Prezi & web & $\mathrm{X}$ & $\mathrm{X}$ & $\mathrm{X}$ & $\mathrm{X}$ & $\mathrm{X}$ & $\mathrm{X}$ \\
\hline $\begin{array}{l}\text { Glogster } \\
\text { Edu }\end{array}$ & web & $\mathrm{X}$ & & $\mathrm{X}$ & & & $\begin{array}{c}\mathrm{X} \\
\text { (compartilha- } \\
\text { mento em } \\
\text { redes sociais } \\
\text { e impressão) }\end{array}$ \\
\hline Gimp & desktop & & & $\mathrm{X}$ & $\mathrm{X}$ & & $\begin{array}{c}\mathrm{X} \\
\text { (impressão) }\end{array}$ \\
\hline
\end{tabular}

Fonte: autoria própria 
6

Por todas estas características é que o Prezi foi escolhido como a ferramenta mais adequada a esta pesquisa.

\section{Estudo de caso na EJA}

A pesquisa relatada neste artigo fez parte do projeto intitulado Poéticas do Corpo, realizado em um Colégio de Aplicação, junto a alunos do segundo ano da EJA de Ensino Médio. O projeto contou com a colaboração da professora de informática e da professora de teatro. Como resultado final, os alunos, em grupo, deveriam produzir infográficos que explicassem a seus colegas (sua audiência) o tema pesquisado (neste caso, a dança e a telenovela).

A oficina de criação dos infográficos durou seis tempos de aula, divididos em dois dias. No primeiro dia, além de explicar como funciona a ferramenta, foi oferecido um tutorial sobre o Prezi (feito na própria ferramenta) e um tutorial sobre princípios de design (alinhamento, repetição, proximidade e contraste), que visavam auxiliar os alunos na construção de seus infográficos. No segundo dia os alunos deram continuidade ao trabalho iniciado. Durante esta etapa, a professora de teatro ficou presente para tirar dúvidas com relação ao conteúdo desenvolvido e havia também uma equipe composta por três pessoas para tirar dúvidas quanto ao manuseio da ferramenta.

A explicação do que era infográfico e exemplos do mesmo foi dada em um momento anterior, de modo que durante a oficina foi apenas relembrado o que era este formato e mostrados mais alguns exemplos.

Para identificação da presença de elementos do letramento multimodal consideraram-se os quatro princípios básicos do design: repetição (repetição de elementos gráficos de mesma importância ou significado), alinhamento (alinhamento entre elementos relacionados ou que possuam a mesma hierarquia/função na mensagem), contraste (diferença entre elementos para dar destaque a um deles, como por exemplo entre cor da fonte e cor de fundo) e proximidade (aproximação espacial entre elementos do design que estão relacionados) (WILLIAMS, 1995).

Considerou-se também a disposição dos elementos na página bem como a integração dos modos no que diz respeito à elaboração de uma mensagem coerente, isto é, que permita ao leitor compreender o que está sendo abordado.

\subsection{Os sujeitos da pesquisa}

Segundo dados da pesquisa CETIC (2011), mostrados nos Gráficos 1 e 2, há um relação inversamente proporcional entre o uso de computadores e internet e a idade dos usuários.

Gráfico 1 - Uso do computador por idade

(CETIC, 2011)
Gráfico 2 - Uso da internet por idade

(CETIC, 2011) 
7
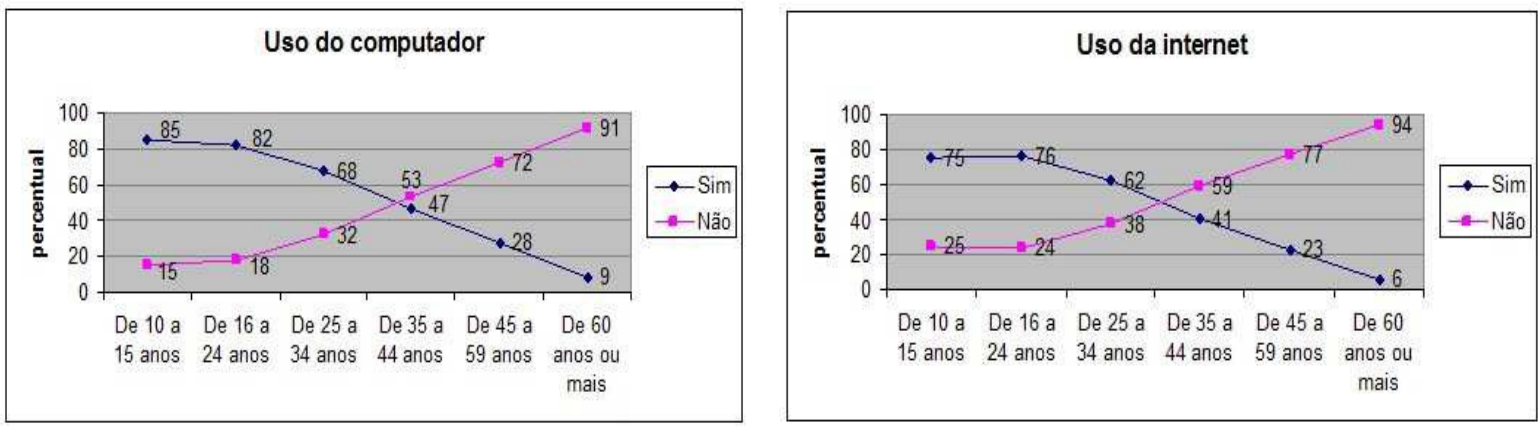

Fonte: CETIC, 2011

Analisando os gráficos, pode-se notar que aproximadamente aos 35 anos de idade há uma inversão no percentual de uso do computador e da internet, quando mais de $50 \%$ da população entrevistada afirma que não usa o computador e a internet. Se pensarmos que vivemos a era da Sociedade da Informação e do Conhecimento - onde o uso do computador e da internet tornaram-se fundamentais para boa parte dos trabalhos realizados (se não para o trabalho como um todo, ao menos para parte dele), bem como para atividades de lazer, acesso à informação, comunicação etc. -, os dados da pesquisa CETIC (2011) tornam-se ainda mais preocupantes tendo em vista que aos 30 anos a pessoa ainda está em idade produtiva. Além disso, o não uso do computador e da internet por essa parcela da população agrava o problema da exclusão digital e social.

Assim, uma vez que a EJA trabalha com alunos que "não tiveram acesso ou continuidade de estudos no ensino fundamental e médio na idade própria” (BRASIL, 1996), é de se supor a necessidade de uma formação voltada para a educação profissional. Neste sentido, pelas vantagens do uso do infográfico já expostas anteriormente, acreditamos que este formato pode contribuir para alavancar e aprimorar os letramentos destes alunos de modo que, ao terminarem o Ensino Médio, estejam mais preparados para ingressar/permanecer no mercado de trabalho e até mesmo buscar um curso superior ou técnico.

A turma onde foi feita a pesquisa é composta por 16 alunos, sendo 9 mulheres e 8 homens com idade entre 18 e 65 anos, com média de idade de 35 anos. Apesar de 12 desses alunos terem computador em casa, inclusive com acesso à Internet, somente cinco deles fazem uso quotidiano desses recursos. Em termos de conhecimentos de informática, a turma, de modo geral, se autoavalia como tendo uma maior familiaridade com habilidades básicas no uso do computador (como usar o mouse, copiar e colar ou navegar na internet), mas apresenta pouca ou nenhuma familiaridade com o uso das ferramentas de autoria classificadas como web 2.0, como criação de um wiki ou um blog, por exemplo.

\subsection{Análise dos resultados}

Com relação aos trabalhos desenvolvidos, o primeiro ponto a ser ressaltado é que não houve, em nenhum dos grupos, a elaboração de um infográfico stricto sensu, como é visto na área do jornalismo. No entanto, por ser uma atividade pedagógica, o objetivo aqui não é tanto a adequação do produto a sua definição, mas sim se houve uma produção que integrou os modos texto e imagem de forma adequada e se a mensagem criada tem um sentido completo, se é uma narrativa (TEIXEIRA, 2010).

Percebeu-se, no grupo da telenovela, que o diagrama da linha do tempo 
8

representou graficamente a ideia do trabalho desenvolvido (neste caso as mudanças físicas da atriz Glória Pires durante seus trabalhos na TV).

Com relação aos princípios do design, houve um uso adequado da repetição da cor, alinhamento e posição dos nomes das novelas, dos anos e dos nomes das personagens. Já o alinhamento entre o título do infográfico, o texto "linha do tempo" e "Glória Pires" mostra o quanto é preciso trabalhar estes conceitos com os alunos, tendo em vista que ficaram soltos na tela, sem referência a nenhum outro elemento do layout.

Outro problema encontrado foi a integração da informação textual com a imagem (Figura 2).

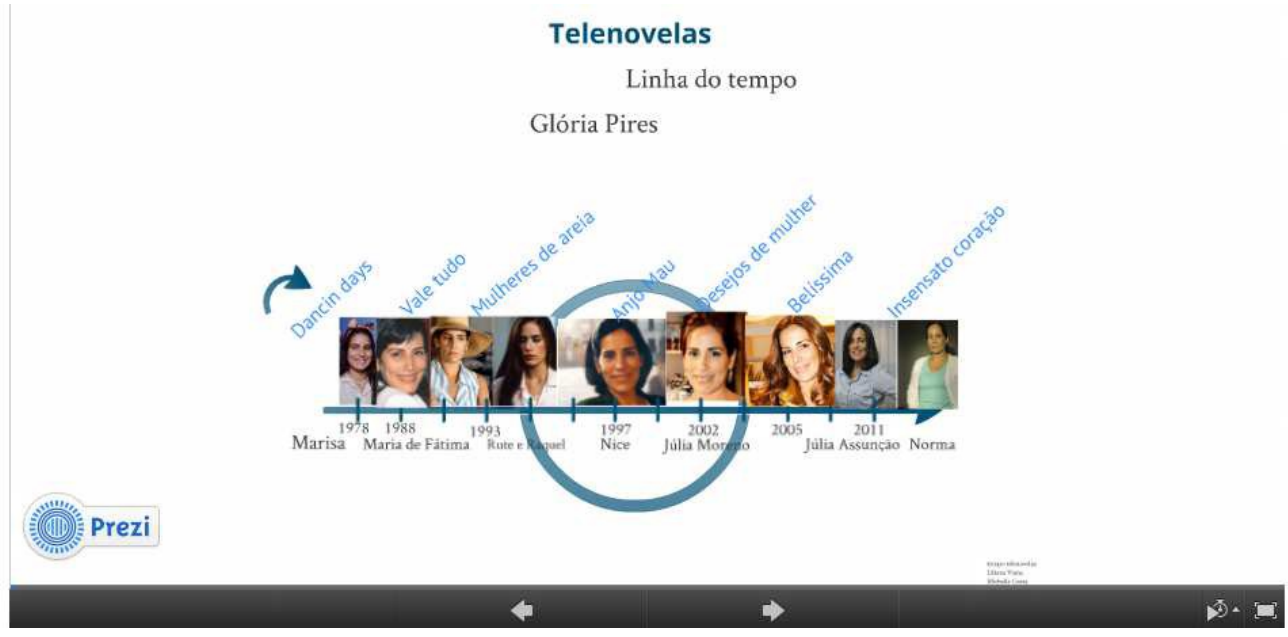

Figura 2 - Infográfico sobre o tema telenovela

Como dito anteriormente, a linha do tempo foi uma escolha acertada para indicar ao leitor a mensagem que ser queria transmitir, mas faltou agregar a este elemento informações valiosas como, por exemplo, associar o aspecto corporal da atriz ao tipo de personagem feito ou mesmo à época em que a novela foi ao ar, de modo a mostrar como o vestuário, cabelo e acessórios usados constituem-se em informações importantes para contar a história. Afinal, como visto, estes elementos também são modos que compõem uma mensagem. Desta forma, considerou-se que a mensagem neste caso ficou incompleta.

O grupo da dança também optou por um dos templates disponíveis no Prezi e o trabalho foi desenvolvido com base nos princípios do design: a repetição do círculo, dos títulos, das fontes e das cores nos elementos semelhantes; a proximidade dos elementos relacionados e o bom contraste entre fonte e fundo. Também houve uma preocupação com o alinhamento dos títulos e dos textos.

Visualmente percebe-se que houve uma divisão das duas danças, de modo que o forró ficou de um lado e a salsa de outro, indicando que há uma oposição/comparação entre as duas danças (Figura 3). 


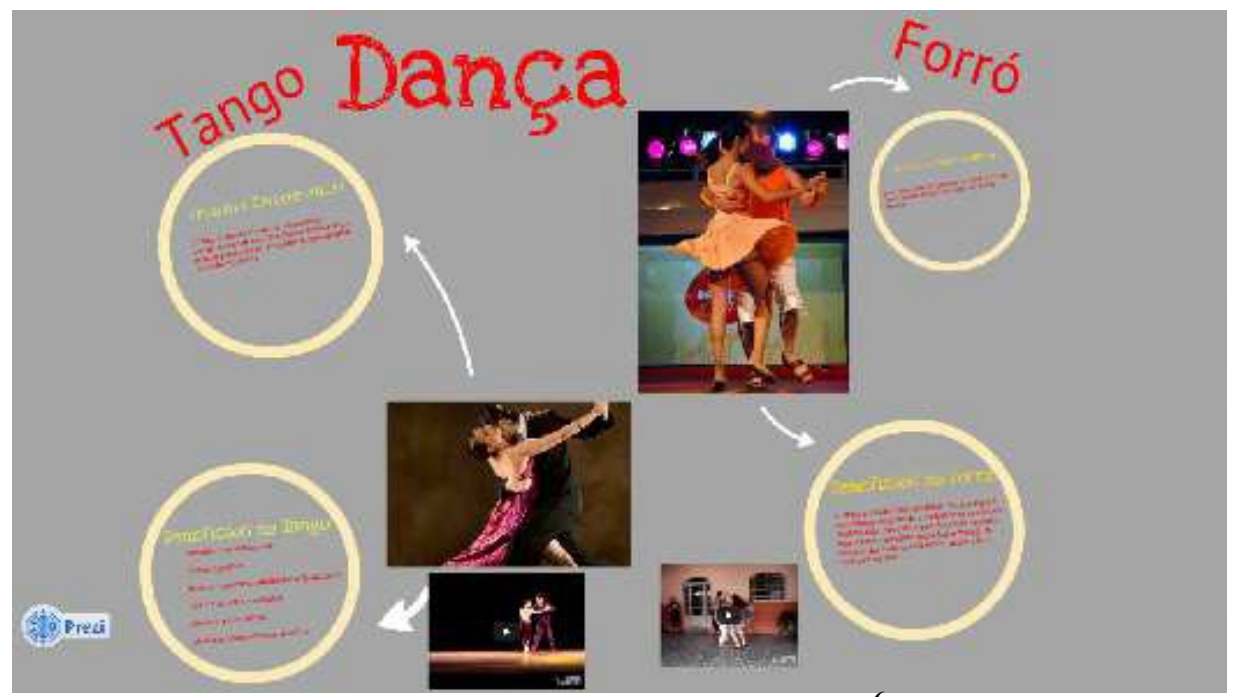

Figura 3 - Infográfico sobre Dança ${ }^{6}$

Esta comparação é complementada pelas imagens escolhidas, que mostram a diferença destes estilos nos trajes dos dançarinos, além dos passos representados. No entanto, essa distinção não é enfatizada no texto verbal, o que gera uma dissonância entre os modos e torna a imagem uma ilustração do texto, isto é, ela tem um papel secundário em relação ao texto verbal.

Complementarmente, o grupo decidiu pela inclusão de um vídeo para explicar melhor as danças, o que mostra uma reflexão acerca das affordances dos modos em relação ao conteúdo explicitado. Em outras palavras, uma vez que o trabalho era sobre o corpo nestas duas danças, o vídeo apresenta-se como o modo mais adequado para representá-lo.

Ainda com relação aos vídeos percebe-se que, em relação aos demais elementos do infográfico, encontram-se um pouco soltos, sendo sua relação com os demais elementos feita somente pela proximidade. Os alunos poderiam ter criado um outro frame para cada um dos vídeos e incluído uma seta para eles (princípio da repetição), o que daria uma unidade gráfica maior ao trabalho. Também há algumas falhas, como a fonte de um dos títulos que não é a mesma dos demais e o corpo dos mesmos, que varia de um círculo para outro. Com relação à integração do texto com a imagem, considerase que o texto, a imagem e o vídeo passaram informações distintas, que não estavam integrados. Mas de modo geral, a assunto pode ser compreendido.

\section{Considerações Finais}

A emergência e difusão das telas em nossa sociedade vem alterando, gradativamente, as formas de ler e escrever. Na tela, a gramática já não se restringe ao texto verbal. Aliado à digitalização da informação, este suporte permite que outros modos como imagem, vídeo, som, deixem de ser meras ilustrações e elementos coadjuvantes do texto escrito e passem a ser também atores, cada um desempenhando um papel específico na representação do conhecimento de acordo com suas affordances.

Nesse sentido, o professor em sala de aula deve oportunizar aos alunos experiências que promovam o letramento multissemiótico dos mesmos, desenvolvendo habilidades "gramaticais” que este novo cenário exige, como os conhecimentos básicos 
10

de design, bem como formas de disposição destes elementos no espaço da tela, que não mais é restrito a linhas e parágrafos.

Mas para que isto ocorra, a escolha do software e a proposta do trabalho a ser desenvolvido devem ser bem definidos, numa escala de dificuldades, para que o aluno possa, ao mesmo tempo, aprender o conteúdo trabalhado e desenvolver habilidades e competências referentes ao letramento multissemiótico.

Os infográficos analisados mostraram que os alunos conseguiram desenvolver seus trabalhos incluindo elementos de design como repetição, proximidade, alinhamento e contraste de forma satisfatória para um primeiro trabalho, apresentando traços de habilidades necessárias ao letramento mutissemiótico. Com relação ao uso dos modos, o trabalho sobre a atriz Glória Pires trouxe a imagem como modo principal, mas deixou a desejar no uso do texto verbal, que não esclarece o porquê daquelas imagens. De modo contrário, o trabalho da dança colocou as informações principais no texto verbal e deixou para a imagem um papel secundário, de ilustrar o tema. Tais dificuldades mostram a importância deste tipo de trabalho junto aos alunos no sentido de desenvolver sua percepção quanto às affordances dos diferentes tipos de representação da informação, pois somente com esta percepção é possível fazer escolhas adequadas dos modos.

Por fim, considera-se que o Prezi é uma ferramenta com potencial para a elaboração de atividades que desenvolvam o letramento multissemiótico dos alunos, pois, apesar dos mesmos terem dificuldade no uso de ferramentas que permitam autoria, conforme os dados do questionário de inclusão digital aplicado, o resultado final tanto em termos de envolvimento dos alunos na atividade quanto em termos de 'despertar' dos mesmos para a importância e utilidade de desenvolver materiais, eles próprios, não meramente “consumirem” materiais prontos disponíveis na Web.

\footnotetext{
${ }^{1}$ Merriam-Webster’s Collegiate. Disponível em: http://www.merriam-webster.com_dictionary/literacy

2 Também conhecido como acontecimento comunicativo, isto é, interação entre pessoas fazendo uso da linguagem.

3 Entende-se aqui as mídias 2.0 como aquelas ferramentas que possibilitam ao usuário produzir, compartilhar e editar conteúdos colaborativamente, seguindo as características que compõem o que chamamos de Web 2.

${ }^{4}$ Social Bakers, 21 mar. 2013, http://www.socialbakers.com/facebook-statistics/

${ }^{5}$ Esta característica torna-se fundamental quando pensamos a escola como um ambiente de criação de materiais didáticos que podem ser reutilizados e adaptados a outros contextos, isto é, um recurso educacional aberto (REA)

${ }^{6}$ http://prezi.com/gjzvitsswdo7/lets-dance/?kw=view-gjzvitsswdo7\&rc=ref-75878
}

\section{Referências}

BRASIL/MEC. Edital de Convocação para o processo de inscrição e avaliação de coleções didáticas para o Programa Nacional Do Livro Didático - PNLD 2014. FNDE/SEB, 2011.

BRASIL/MEC. Lei de Diretrizes e Bases da Educação Nacional. Brasília: MEC, 1996. Disponível em: <http://portal.mec.gov.br/arquivos/pdf/ldb.pdf>. Acesso em: 5 maio 2013.

CETIC. Pesquisa sobre o Uso das Tecnologias da Informação e da Comunicação no 
Brasil - TIC Educação 2010. São Paulo: Comitê Gestor da Internet no Brasil, 2011. Disponível em: http://www.cetic.br/educacao/2011/. Acesso em: 5 maio 2013.

COSTA, Valéria, TAROUCO Liane e BIAZUS, Maria Cristina. Criação de Objetos de Aprendizagem baseados em infográficos. VI Congresso Latinoamericano de Objetos de Aprendizagem, 2011. Montevidéu. Anais... Disponível em: $<$ http://laclo2011.seciu.edu.uy/publicacion/laclo/laclo2011_submission_68.pdf>. Acesso em: 5 maio 2013.

JEWITT, Carey; KRESS, Gunther (Orgs). Multimodal Literacy. New York: Peter Lang, 2008.

KLEIMAN, Angela B. Modelos de letramento e as práticas de alfabetização na escola. In: _ (Org). Os significados do letramento: uma nova perspectiva sobre a prática social da escrita. Campinas: Mercado de Letras, 2008.

KRESS, Gunther. Literacy in the new media age. Londres: Routledge, 2011.

. Multimodality: a social semiotic approach to contemporary communication. Nova Iorque: Routledge, 2010.

MAYER, Richard. Multimedia Literacy. In: COIRO, Julie et al. (Eds.). Handbook of research on new literacies. New York: Lawrence Erlbaum Associates, 2008.

ROJO, Roxane. Letramentos múltiplos, escola e inclusão social. São Paulo: Parábola Editorial, 2009.

TEIXEIRA, Tattiana. Infografia e Jornalismo: conceitos, análises e perspectivas. Salvador: EDUFBA, 2010.

WARSCHAUER, Mark. Tecnologia e inclusão social: a exclusão digital em debate. São Paulo: Senac São Paulo, 2006.

WILLIAMS, Robin. Design para quem não é designer. São Paulo: Callis, 1995. 